BNL-NCS-63766

Informal Report

\title{
Measurement and Basic Physics Committee of the U.S. Cross-Section Evaluation Working Group
}

REGEUVED

FEB 069997

OSTI

\author{
Annual Report 1996 \\ by \\ Donald L. Smith, Chairman \\ Argonne National Laboratory \\ and \\ Victoria McLane \\ Brookhaven National Laboratory
}

Compiled and Edited at Argonne National Laboratory

November 1996

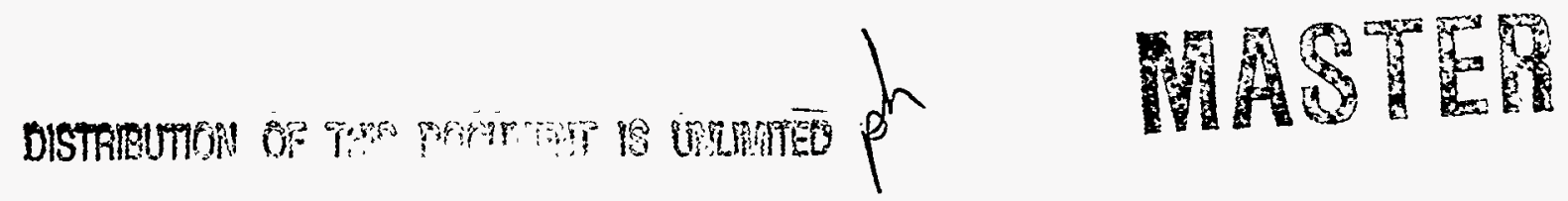

National Nuclear Data Center

Brookhaven National Laboratory

Upton, NY 11973-5000 


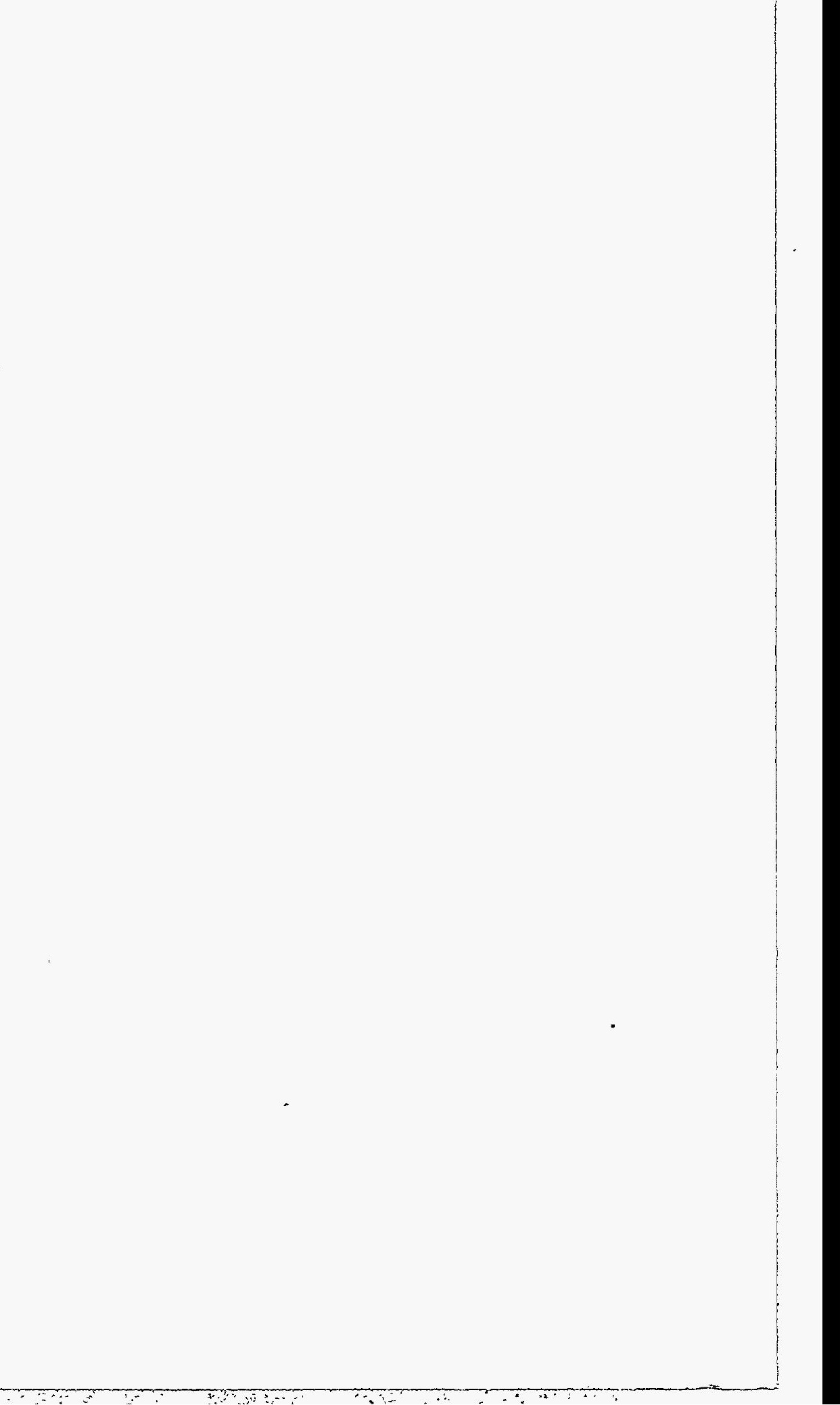




\section{DISCLAIMER}

Portions of this document may be illegible in electronic image products. Images are produced from the best available original document. 
BNL-NCS-63766

Informal Report

\section{Measurement and Basic Physics \\ Committee of the U.S. Cross-Section Evaluation Working Group}

Annual Report 1996

by

Donald L. Smith, Chairman

Argonne National Laboratory

and

Victoria McLane

Brookhaven National Laboratory

Compiled and Edited at Argonne National Laboratory

November 1996

National Nuclear Data Center

Brookhaven National Laboratory

Upton, NY 11973-5000 


\section{DISCLAIMER}

This report was prepared as an account of work sponsored by an agency of the United States Government. Neither the United States Government nor any agency thereof, nor any of their employees, not any of their contractors, subcontractors, or their employees, makes any warranty, express or implied, or assumes any legal liability or responsibility for the accuracy, completeness, or usefulness of any information, apparatus, product, or process disclosed, or represents that its use would not infringe privately owned rights. Reference herein to any specific commercial product, process, or service by trade name trademark, manufacturer, or otherwise, does not necessarily constitute or imply its endorsement, recommendation, or favoring by the United States Government or any agency, contractor, or subcontractor thereof. The views and opinions of authors expressed herein do not necessarily state or reflect those of the United States Government or any agency, contractor or subcontractor thereof. 


\section{TABLE OF CONTENTS}

Introduction $\ldots \ldots \ldots \ldots \ldots \ldots \ldots \ldots \ldots \ldots \ldots \ldots \ldots \ldots \ldots \ldots \ldots \ldots \ldots \ldots$

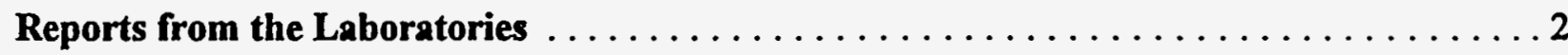

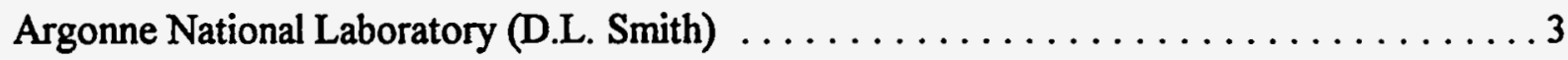

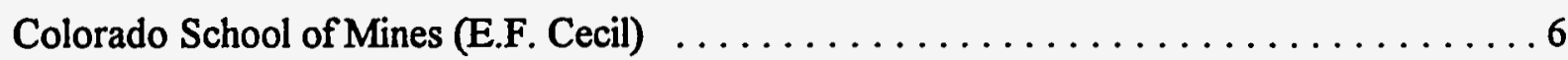

Los Alamos National Laboratory (R.C. Haight) $\ldots \ldots \ldots \ldots \ldots \ldots \ldots \ldots \ldots \ldots$

National Institute of Standards and Technology (A.D. Carlson) $\ldots \ldots \ldots \ldots \ldots$

Oak Ridge National Laboratory (M.S. Smith) $\ldots \ldots \ldots \ldots \ldots \ldots \ldots \ldots \ldots \ldots \ldots \ldots$

Ohio University (S.M. Grimes and T.N. Massey) $\ldots \ldots \ldots \ldots \ldots \ldots \ldots \ldots \ldots \ldots \ldots \ldots \ldots \ldots$

Pacific Northwest Laboratory (P.L. Reeder) $\ldots \ldots \ldots \ldots \ldots \ldots \ldots \ldots \ldots \ldots \ldots \ldots \ldots$

University of California-Davis (J.L. Romero) $\ldots \ldots \ldots \ldots \ldots \ldots \ldots \ldots \ldots \ldots \ldots \ldots \ldots \ldots$

University of Kentucky-Lexington (M.T. McEllistrem) $\ldots \ldots \ldots \ldots \ldots \ldots \ldots \ldots \ldots$

University of Massachusetts-Lowell (J.J. Egan) $\ldots \ldots \ldots \ldots \ldots \ldots \ldots \ldots \ldots \ldots \ldots \ldots$

University of Wisconsin-Madison (H.H. Barschall) $\ldots \ldots \ldots \ldots \ldots \ldots \ldots \ldots \ldots \ldots \ldots \ldots \ldots$

CSEWG Measurement and Basic Science Committee Membership ............ 27 


\section{INTRODUCTION}

The Cross-Section Evaluation Working Group (CSEWG) is a long-standing committee charged with the responsibility for organizing and overseeing the U.S. cross-section evaluation effort. It's main product is the official U.S. evaluated nuclear data file, ENDF. The current version of this file is Version VI. All evaluations included in ENDF are reviewed and approved by CSEWG and issued by the U.S. Nuclear Data Center, Brookhaven National Laboratory. CSEWG is comprised of volunteers from the U.S. nuclear data community who possess expertise in evaluation methodologies and who collectively have been responsible for producing most of the evaluations included in ENDF.

In 1992 CSEWG added the Measurements Committee to its list of standing committees and subcommittees. This action was based on a recognition of the importance of experimental data in the evaluation process as well as the realization that measurement activities in the U.S. were declining at an alarming rate and needed all possible encouragement to avoid the loss of this resource. The mission of the Committee is to maintain a network of experimentalists in the U.S. that would provide needed encouragement to the national nuclear data measurement effort through improved communication and facilitation of collaborative activities. In 1994, an additional charge was added to the responsibilities of this Committee, namely, to serve as an interface between the more applied interests represented in CSEWG and the basic nuclear science community. Its name was then changed to the Measurement and Basic Physics Committee. The Committee currently has 19 members, and interested scientists are welcome to join the network by simply contacting the Chairman. For reference, the names of the current members and contact information are contained in this report.

This annual report is the second such document issued by the Committee. It contains voluntary contributions from eleven laboratories in the U.S. which have been prepared by members of the Committee and submitted to the Chairman for compilation and editing. This report is being distributed in hard copy and is also available on-line via the National Nuclear Data Center, Brookhaven National Laboratory. It is hoped that the information provided here on the work that is going on at the reporting laboratories will prove interesting and stimulating to the readers.

Donald L. Smith, Chairman

CSEWG Measurement and Basic Science Committee

Argonne National Laboratory

November 1996 


\section{REPORTS FROM THE LABORATORIES}

The following reports appear alphabetically in order of the submitting laboratory. The individuals who prepared the reports at the various laboratories are indicated along with a contact address for reference. Titles of individual contributions, and names of the contributors, appear as titled subheadings within each laboratory report. Note that there may be some duplication of the topical material submitted by the reporting laboratories. This is inevitable given the extensive and very desirable ongoing collaborations between several of these organizations. 


\title{
Argonne National Laboratory
}

\author{
Contact: D.L. Smith \\ Technology Development Division \\ TD-207-DB116 \\ Argonne National Laboratory \\ Argonne, Illinois 60439
}

\section{Development of New Nuclear Techniques for Technological Applications}

D. L. Smith, B.J. Micklich, C. Fink and I.C. Gomes (Argonne National Laboratory), Y. Ikeda, Y. Uno and F. Maekawa (Japan Atomic Energy Research Institute, Japan) and A.A. Filatenkov (Khlopin Radium Institute, Russia)

A new approach to fast-neutron dosimetry has been investigated. It involves circulating a liquid with dissolved chemicals between a localized neutron field and a remote area where neutron-induced radioactivities are measured continuously. This approach employs reactions which generate relatively short-lived radioactive byproducts. Sensitivity to the neutron-energy spectrum is achieved by choosing several reactions with differing thresholds. Neutron field strengths and their time variations can be derived from experimental data using the known radioactive-decay properties, cross sections, detector efficiencies, liquid flow rates and composition of the liquid. The concept has been demonstrated by measurements which utilized an aqueous solution of yttrium chloride hexahydrate, a $14-\mathrm{MeV}$ neutron generator and $\mathrm{Ge}$ gamma-ray detectors. The ${ }^{16} \mathrm{O}(\mathrm{n}, \mathrm{p}){ }^{16} \mathrm{~N},{ }^{37} \mathrm{Cl}(\mathrm{n}, \mathrm{p}){ }^{3 \mathrm{~s}}$ and ${ }^{89} \mathrm{Y}\left(\mathrm{n}, \mathrm{n}^{\prime}\right)^{89 \mathrm{~m}} \mathrm{Y}$ activation reactions served as dosimeters. The results from this investigation have been reported at a recent conference [1]. A new approach to photon radiography based on gamma rays from the decay of ${ }^{16} \mathrm{O}$ excited states produced by either the ${ }^{19} \mathrm{~F}(\mathrm{p}, \alpha \gamma){ }^{16} \mathrm{O}$ or ${ }^{16} \mathrm{O}(\mathrm{n}, \mathrm{p}){ }^{16} \mathrm{~N}(\beta-)^{16} \mathrm{O}$ reactions is being explored. A paper on this work has been published [2] and a proposal for future work is being developed.

\section{Cross Section Measurements}

D.L. Smith and J.W. Meadows (Argonne National Laboratory), R.C. Haight (Los Alamos National Laboratory), L. Greenwood (Pacific Northwest National Laboratory), W. Mannhart (Physikalisch Technische Bundesanstalt, Germany), Y. Ikeda, Y. Uno and F. Maekawa (Japan Atomic Energy Research Institute, Japan) and A. Fessler and E. Wattecamps (Institute for Reference Materials and Measurements, Belgium)

Analysis of neutron activation cross-section data measured from 13-15 MeV at JAERI, Japan, is progressing for ${ }^{11} \mathrm{~B}(\mathrm{n}, \mathrm{p}){ }^{11} \mathrm{Be},{ }^{16} \mathrm{O}(\mathrm{n}, \mathrm{p}){ }^{16} \mathrm{~N},{ }^{19} \mathrm{~F}(\mathrm{n}, \alpha){ }^{16} \mathrm{~N},{ }^{19} \mathrm{~F}(\mathrm{n}, \mathrm{p})^{19} \mathrm{O},{ }^{23} \mathrm{Na}(\mathrm{n}, \mathrm{p}){ }^{23} \mathrm{Ne},{ }^{28} \mathrm{Si}(\mathrm{n}, \mathrm{p})^{28} \mathrm{Al}$, ${ }^{37} \mathrm{Cl}(\mathrm{n}, \mathrm{p}){ }^{37} \mathrm{~S},{ }^{46} \mathrm{Ti}(\mathrm{n}, \mathrm{p}){ }^{46 \mathrm{Sc}} \mathrm{Sc},{ }^{52} \mathrm{Cr}(\mathrm{n}, \mathrm{p}){ }^{52} \mathrm{~V},{ }^{53} \mathrm{Cr}(\mathrm{n}, \mathrm{p}){ }^{33} \mathrm{~V},{ }^{55} \mathrm{Mn}(\mathrm{n}, \alpha)^{52} \mathrm{~V},{ }^{89} \mathrm{Y}\left(\mathrm{n}, \mathrm{n}^{1}\right)^{89 \mathrm{~m}} \mathrm{Y},{ }^{119} \mathrm{Sn}(\mathrm{n}, \mathrm{p}){ }^{119 \mathrm{~m}} \mathrm{In}$, ${ }^{138} \mathrm{Ba}(\mathrm{n}, 2 \mathrm{n})^{137 \mathrm{~m}} \mathrm{Ba}, \quad{ }^{141} \mathrm{Pr}(\mathrm{n}, 2 \mathrm{n}){ }^{140} \mathrm{Pr}, \quad{ }^{186} \mathrm{~W}(\mathrm{n}, 2 \mathrm{n}){ }^{185 \mathrm{~m}} \mathrm{~W}, \quad{ }^{204} \mathrm{~Pb}(\mathrm{n}, 2 \mathrm{n}){ }^{203 \mathrm{~m}} \mathrm{~Pb}, \quad{ }^{64} \mathrm{Ni}(\mathrm{n}, \mathrm{np}){ }^{63} \mathrm{Co}$, ${ }^{179} \mathrm{Hf}(\mathrm{n}, 2 \mathrm{n})^{178 \mathrm{~m} 2} \mathrm{Hf}$ and various reactions involving isotopes of $\mathrm{Te}$ and $\mathrm{Tl}$. The results from neutron activation cross-section measurements for $\mathrm{Ag}, \mathrm{Fe}, \mathrm{Ni}, \mathrm{Ti}, \mathrm{Hf}, \mathrm{Tb}, \mathrm{Eu}$ and $\mathrm{Cu}$, pursued as part of a multinational collaboration coordinated by the IAEA, have been published [3]. Cross sections have been measured from 6-15 MeV for the ${ }^{52} \mathrm{Cr}(\mathrm{n}, \mathrm{p}){ }^{52} \mathrm{~V},{ }^{52} \mathrm{Cr}(\mathrm{n}, 2 \mathrm{n}){ }^{51} \mathrm{Cr},{ }^{51} \mathrm{~V}(\mathrm{n}, \mathrm{p}){ }^{51} \mathrm{Ti}$ and ${ }^{51} \mathrm{~V}(\mathrm{n}, \alpha){ }^{48} \mathrm{Sc}$ 
reactions and data analysis is progressing for this joint project with PTB-Braunschweig. Cross sections have also been measured from 16-20 MeV at IRMM, Belgium, for the following reactions: ${ }^{57} \mathrm{Fe}(\mathrm{n}, \mathrm{p}){ }^{57} \mathrm{Mn}, \quad{ }^{57} \mathrm{Fe}(\mathrm{n}, \mathrm{np}){ }^{56} \mathrm{Mn}, \quad{ }^{54} \mathrm{Fe}(\mathrm{n}, 2 \mathrm{n}){ }^{53} \mathrm{Fe},{ }^{54} \mathrm{Fe}(\mathrm{n}, 2 \mathrm{n}){ }^{33 \mathrm{~m}} \mathrm{Fe},{ }^{52} \mathrm{Cr}(\mathrm{n}, \mathrm{p}){ }^{52} \mathrm{~V},{ }^{23} \mathrm{Na}(\mathrm{n}, \mathrm{p}){ }^{23} \mathrm{Ne}$, ${ }^{23} \mathrm{Na}(\mathrm{n}, \alpha){ }^{20} \mathrm{~F},{ }^{25} \mathrm{Mg}(\mathrm{n}, \mathrm{p}){ }^{25} \mathrm{Na},{ }^{29} \mathrm{Si}(\mathrm{n}, \mathrm{p})^{29} \mathrm{Al}$, ratio $\{\mathrm{Al}(\mathrm{n}, \mathrm{p}) / \mathrm{Al}(\mathrm{n}, \alpha)\},{ }^{35} \mathrm{Cl}(\mathrm{n}, 2 \mathrm{n}){ }^{34} \mathrm{Cl},{ }^{28} \mathrm{Si}(\mathrm{n}, \mathrm{p})^{28} \mathrm{Al}$, ${ }^{37} \mathrm{Cl}(\mathrm{n}, \mathrm{p}){ }^{37} \mathrm{~S}$, ratio $\{\mathrm{Al}(\mathrm{n}, \alpha) / \mathrm{Nb}(\mathrm{n}, 2 \mathrm{n})\},{ }^{54} \mathrm{Fe}(\mathrm{n}, \mathrm{t})^{52 \mathrm{~m}} \mathrm{Mn},{ }^{46} \mathrm{Ti}(\mathrm{n}, \mathrm{p}){ }^{46 \mathrm{~m}} \mathrm{Sc},{ }^{35} \mathrm{Mn}(\mathrm{n}, \alpha){ }^{52} \mathrm{~V},{ }^{119} \mathrm{Sn}(\mathrm{n}, \mathrm{p}){ }^{119} \mathrm{In}$, $\left.{ }^{138} \mathrm{Ba}(\mathrm{n}, 2 \mathrm{n}){ }^{137 \mathrm{~m}} \mathrm{Ba},{ }^{50} \mathrm{Ti}(\mathrm{n}, \mathrm{p}){ }^{50} \mathrm{Sc},{ }^{54} \mathrm{Cr}(\mathrm{n}, \mathrm{np}){ }^{53} \mathrm{~V},{ }^{93} \mathrm{Nb}(\mathrm{n}, \alpha)\right)^{92 \mathrm{~m}} \mathrm{Nb},{ }^{54} \mathrm{Cr}(\mathrm{n}, \mathrm{p}){ }^{54} \mathrm{~V},{ }^{54} \mathrm{Cr}(\mathrm{n}, \alpha){ }^{51} \mathrm{Ti}$, ${ }^{53} \mathrm{Cr}(\mathrm{n}, \mathrm{p}){ }^{53} \mathrm{~V},{ }^{62} \mathrm{Ni}(\mathrm{n}, \mathrm{p}){ }^{644} \mathrm{Co},{ }^{62} \mathrm{Ni}(\mathrm{n}, \mathrm{p}){ }^{62 \mathrm{~m}} \mathrm{Co},{ }^{53} \mathrm{Cr}(\mathrm{n}, \mathrm{np}){ }^{52} \mathrm{~V},{ }^{31} \mathrm{~V}(\mathrm{n}, \mathrm{p}){ }^{51} \mathrm{Ti},{ }^{31} \mathrm{P}(\mathrm{n}, \alpha){ }^{28} \mathrm{Si},{ }^{16} \mathrm{O}(\mathrm{n}, 2 \mathrm{n}){ }^{15} \mathrm{O}$, ${ }^{19} \mathrm{~F}(\mathrm{n}, \mathrm{p}){ }^{19} \mathrm{O}$ and ${ }^{11} \mathrm{~B}(\mathrm{n}, \mathrm{p}){ }^{11} \mathrm{Be}$. Isotopically-enriched samples obtained from JAERI, Japan, and IRMM, Belgium, as well as elemental sample materials were used for this investigation.

\section{${ }^{53}$ V Half-life Measurement}

D.L. Smith (Argonne National Laboratory) and A. Fessler and E. Wattecamps (Institute for Reference Materials and Measurements, Belgium)

${ }^{53} \mathrm{~V}$ was generated via the ${ }^{53} \mathrm{Cr}(\mathrm{n}, \mathrm{p})^{53} \mathrm{~V}$ reaction using an elemental $\mathrm{Cr}$ sample and neutrons of around $17 \mathrm{MeV}$ generated at the IRMM Van de Graaff accelerator facility via the ${ }^{3} \mathrm{H}(\mathrm{d}, \mathrm{n})^{4} \mathrm{He}$ source reaction. Twenty five independent decay curves were generated by successive irradiations of the sample, and for each of these the activity was followed over a range of about two orders of magnitude. The objective is to improve the knowledge of the half life to better than $1 \%$ accuracy from the present level of about $3 \%$ accuracy. These data are being analyzed.

Data Compilation and the Derivation of Reaction Rates at Stellar Energies for $(p, \gamma)$ and $(p, \alpha)$ Reactions in the Mass Range $A=30-50$

\section{D.L. Smith (Argonne National Laboratory), M. Wiescher (University of Notre Dame), J. Daly (Indiana University-South Bend), L. Van Wormer (Hiram College)}

Reactions of the type $(p, \gamma)$ and $(p, \alpha)$ play important roles in stellar nucleosynthesis. The objective of this work has been to compile data on these specific reactions, and on the compound nuclei which are formed, for the mass range $A=30-50$. This project is part of a larger international endeavor to improve the data base of nuclear reaction information employed in astrophysical analyses. Using this collected information, reaction rates and their associated uncertainties are being determined at center-of-mass interaction energies corresponding to Maxwell-Boltzmann distributions for stellar temperatures which range from $\mathrm{T} 9=0.01$ to 10 in units of $10^{9}$ degree Kelvin, i.e., for $\mathrm{kT}=0.86$ to $860 \mathrm{keV}$. Depending upon the individual reactions and compound nuclear systems formed, reaction rates under these conditions may be dominated by a few isolated resonances, by so many resonances that they can be treated statistically, or by any intermediate combination. Regardless of the situation, the calculated reaction rates are found to be extremely sensitive to the stellar temperature T9. To date this effort has focused on the following specific reactions: ${ }^{31} \mathrm{P}(\mathrm{p}, \gamma)^{32} \mathrm{~S}$, ${ }^{31} \mathrm{P}(\mathrm{p}, \alpha){ }^{28} \mathrm{Si}$ and ${ }^{32} \mathrm{~S}(\mathrm{p}, \gamma){ }^{33} \mathrm{Cl}$. Summaries of pertinent references found in the literature have been prepared and files of data published therein have been assembled in the EXFOR format for convenient transmittal to data centers. Reaction-rate calculations have been performed based on consideration of both known individual resonances and the Hauser-Feshbach approach which can treat the compound nucleus as a continuum of levels. Uncertainty estimates for these reaction rates have also 
been generated. They are based on the propagation of errors in individual parameters which enter into the reaction-rate calculations.

[1] D.L. Smith, Y. Ikeda and F. Maekawa, Ninth International Conference on Reactor Dosimetry, Prague, Czech Republic, 2-6 September 1996.

[2] D.L. Smith, Y. Ikeda and Y. Uno, Fusion Engineering and Design 31, 41 (1996).

[3] J.W. Meadows, D.L. Smith, L.R. Greenwood, R.C. Haight, Y. Ikeda and C. Konno, Annals of Nuclear Energy 23, 877 (1996). 


\section{Colorado School of Mines}

Contact: F.E. Cecil

Physics Department

Colorado School of Mines

Golden, Colorado 80401

\section{Low Energy Nuclear Reaction Studies at Colorado School of Mines}

\section{F.E. Cecil (Colorado School of Mines)}

We have completed a major round of experiments on the exothermic $(d, p),(d, t)$ and $(d, \alpha)$ reactions on ${ }^{7} \mathrm{Li},{ }^{9} \mathrm{Be},{ }^{10} \mathrm{~B}$ and ${ }^{11} \mathrm{~B}$. The results of the measurements were reported at the recent "Nuclei in the Cosmos" Conference at Notre Dame [1] and have been submitted to Phys. Rev. C. In addition to our ongoing theoretical efforts at understanding these results, we are undertaking the investigation of two important related topics:

1) Measurement of charged particle producing exothermic nuclear reactions induced by protons and deuterons on light nuclei at forward angles (including zero degrees) by use of the "thin-thick target method" where the beam stops in the target while the reaction product can pass through the target and be detected in transmission geometry with an acceptable degree of energy straggling. We have tested this method using the $d-d$ and $d-B$ reaction with very encouraging results.

2) Measurement of the (d,n) reactions on light nuclei (up to ${ }^{11} B$ ). We have acquired a large CB scintillation spectrometer and are developing the hardware to carry out the measurements in the very near future.

[1] E. Cecil, Fourth International Conference on Nuclei in the Cosmos, University of Notre Dame, Notre Dame, Indiana, 20-27 June 1996. 


\title{
Los Alamos National Laboratory
}

\author{
Contact: R.C. Haight
}

Group P-15, MS-D

Los Alamos National Laboratory

Los Alamos, New Mexico 87545

\section{Neutron-proton Scattering at $10 \mathrm{MeV}$}

R.C. Haight (Los Alamos National Laboratory), O.D. Wasson and A.D. Carlson (National Institute of Standards and Technology), T.N. Massey, S.M. Grimes, F.B. Bateman, C.E. Brient and Ch. Elster (Ohio University) and H. Zhou (Beijing Normal University, China)

The relative angular distribution of neutron-proton scattering at $10 \mathrm{MeV}$ was measured at the Ohio University Accelerator Laboratory by a group from Ohio University, Los Alamos National Laboratory, NIST and Beijing Normal University. The angular range subtended was from 60 to 180 degrees in the center of mass, in 24-degree steps. The results from 108 to 180 degrees (taken simultaneously) give a consistent picture in agreement with phase-shift analyses at accuracies approaching $1 \%$. The more forward-angle data are planned to be remeasured.

\section{${ }^{10} \mathbf{B}(\mathbf{n}, \alpha \gamma)$ Cross Section}

A.D. Carlson, R. Schrack and O.D. Wasson (National Institute of Standards and Technology) and P. Staples and R.C. Haight (Los Alamos National Laboratory)

The cross section of the ${ }^{10} \mathrm{~B}(\mathrm{n}, \alpha \gamma)^{7} \mathrm{Li}(0.478 \mathrm{MeV})$ reaction was measured at WNR by detection of the de-excitation gamma ray in ${ }^{7} \mathrm{Li}$. The neutron energy range is approximately 0.1 to $20 \mathrm{MeV}$. This cross section is an important neutron-flux measurement standard. Final data were obtained in 1995 with lower uncertainties than were achieved in earlier data runs on this experiment. The data are presently under analysis.

\section{${ }^{58,60} \mathrm{Ni}(\mathbf{n}, \mathbf{x} \alpha)$ Reactions}

R.C. Haight, F.B. Bateman and S.M. Sterbenz (Los Alamos National Laboratory), S.M. Grimes (Ohio University), O.D. Wasson (National Institute of Standards and Technology), H. Vonach (Institut fuer Radiumforschung und Kernphysik, Austria) and P. Maier-Komor (Technical University-Munich, Germany)

Alpha-particles emitted in the interaction of neutrons with ${ }^{58} \mathrm{~N}$ and ${ }^{60} \mathrm{Ni}$ have been studied and cross sections, emission spectra and angular distributions have been obtained for incident neutron energies from threshold to $50 \mathrm{MeV}$. In the region of nuclear data evaluations (up to $20 \mathrm{MeV}$ ), significant differences were found between these results and ENDF/B-VI, except near $14 \mathrm{MeV}$. The present results, however, are consistent with other measurements reported in the literature. Thus it is concluded that normalization of calculations at one energy (e.g., $14 \mathrm{MeV}$ ) can give erroneous results at other energies. 


\section{${ }^{59} \mathrm{Co}(\mathrm{n}, \mathbf{x \alpha})$ Reaction}

R.W. Finlay (Ohio University), F.S. Dietrich (Lowrence Livermore National Laboratory) and

W. Abfalterer, G.L. Morgan, J.L. Ullmann and R.C. Haight (Los Alamos National Laboratory)

Alpha-particles emitted in the interaction of neutrons with ${ }^{59} \mathrm{Co}$ have been studied and cross sections, emission spectra and angular distributions have been obtained for incident neutron energies from threshold to $50 \mathrm{MeV}$. A paper has been accepted for publication by Nuclear Science and Engineering.

\section{Total Cross Sections from 5 to $600 \mathrm{MeV}$}

\section{P. Staples and K. Morley (Los Alamos National Laboratory)}

Total cross section data are required for further improvements in the optical model. It is planned to measure a range of materials from $\mathrm{H}$ through $\mathrm{U}$ to complement the previous measurements by Finlay et al. (Ohio University and Los Alamos National Laboratory).

\section{Fission Cross Sections}

P. Staples, K. Morley, A. Gavron and P. Lisowski (Los Alamos National Laboratory)

As indicated in the 1995 report, neutron-induced fission cross sections over the range 0.5 to $300 \mathrm{MeV}$ have been measured for ${ }^{239,240,242,244} \mathrm{Pu},{ }^{197} \mathrm{Au}$, natural $\mathrm{Pb}$ and ${ }^{209} \mathrm{Bi}$ relative to the ${ }^{235} \mathrm{U}$ fission cross section. Final reports and papers are being prepared.

\section{${ }^{238} \mathbf{U}(\mathbf{n}, \mathbf{x n} \gamma)$ Reaction}

R.O. Nelson and S.A. Wender (Los Alamos National Laboratory), J.A. Becker, L.A. Bernstein and M.A. Stoyer (Lawrence Livermore National Laboratory) and N.R. Roberson (Triangle Universities Nuclear Laboratory)

Preliminary high-resolution measurements of neutron-induced reactions on ${ }^{238} U$ were conducted at the WNR neutron source for neutron energies from 3 to $30 \mathrm{MeV}$. Excitation functions were extracted for a number of gamma rays from the $\left(n, n^{\prime}\right)$ and $(n, 3 n)$ reactions. This experiment serves as a feasibility study for planned ${ }^{239} \mathrm{Pu}(\mathrm{n}, \mathrm{xn} \gamma)$ measurements. 


\section{National Institute of Standards and Technology}

Contact: A.D. Carlson

National Institute of Standards and Technology

Building 245, Room C314

Gaithersburg, MD 20899

\section{Measurement Program}

\section{A.D. Carlson, R.A. Schrack and O.D. Wasson (National Institute of Standards and Technology)}

This measurements program continues at a modest level with studies of important neutron cross section standards which are needed for improved determinations of neutron cross sections and neutron fluence. This group continues to collaborate in experiments at available neutron facilities and encourages measurements there to improve the standards.

\section{The H(n,p) Angular Distribution at $10 \mathrm{MeV}$ Neutron Energy}

R.C. Haight and F.B. Bateman (Los Alamos National Laboratory), S.M. Grimes, C.E. Brient and T.N. Massey (Ohio University), A.D. Carlson and O.D. Wasson (National Institute of Standards and Technology) and H. Zhou (Beijing Normal University, China)

The hydrogen scattering cross section is one of the most important neutron cross section standards. The approximately $3 \%$ differences between the ENDF/B-V and ENDF/B-VI evaluations of this important standard cross section in the $10-\mathrm{MeV}$ energy region led to undertaking a new measurement to improve the quality of this standard. This experiment was performed at the Ohio University Tandem Accelerator facility. Preliminary measurements were made of the angular distribution from 60 to 180 degrees in the center of mass by detecting recoil protons. Although the uncertainties place limits on the present results, these data suggest that the problem may be with the ENDF/B-VI hydrogen evaluation. Further data taking is planned next year to reduce the statistical uncertainty and to make an improvement in the experiment by using the same electronic system for all detectors so that the dead time losses are the same for all detectors.

\section{Measurements Supporting Improvements in the ${ }^{10} \mathrm{~B}(\mathrm{n}, \alpha)$ Cross Section Standards}

R.A. Schrack, A.D. Carlson and O.D. Wasson (National Institute of Standards and Technology) and P. Staples and R.C. Haight (Los Alamos National Laboratory)

As part of an NEANSC-endorsed interlaboratory collaboration to extend the usefulness of the ${ }^{10} \mathrm{~B}(\mathrm{n}, \alpha)$ standard cross section to higher neutron energies, measurements have been made of the shape of the ${ }^{10} \mathrm{~B}\left(\mathrm{n}, \alpha_{1} \gamma\right)$ cross section using the WNR facility at the LAMPF accelerator at Los Alamos National Laboratory. For this work, the neutron fluence was measured using the ${ }^{235} U(n, f)$ reaction, and the ${ }^{10} \mathrm{~B}\left(n, \alpha_{1} \gamma\right)$ reaction rate was determined by detecting the $478-\mathrm{keV}$ photons from this reaction with an intrinsic Ge detector. Preliminary measurements of this cross section were made in 
the fall of 1994, however the experiment was limited by the time which was available. Cross-section data were obtained for the energy interval from 0.3 to $12 \mathrm{MeV}$. The results are in good agreement with an earlier measurement from this program in the 0.2 to $4 \mathrm{MeV}$ neutron energy region made at the ORELA facility at Oak Ridge National Laboratory [1]. This work thus verifies the deviation from the ENDF/B-VI evaluation seen in the earlier measurement for energies greater than $2 \mathrm{MeV}$. In the fall of 1995, further measurements were made at WNR with the hope of increasing the statistical accuracy and providing a more accurate normalization for the data by extending the measurement to lower energies where the existing standard is defined more accurately. This experiment was not successful. Further work on this cross section is being considered using a new facility at WNR. The need for very accurate cross section measurements for special applications in such fields as astrophysics requires the standards to be determined to even higher accuracies than they are now known. There is a strong need for better standards in the keV energy region. Often such measurements use a thermal normalization. A measurement of the ${ }^{10} \mathrm{~B}$ total cross section at very low energies (about $4 \mathrm{meV}$ ) at the NIST reactor is now being planned. The scattering cross section is small and well known so the ${ }^{10} \mathrm{~B}(\mathrm{n}, \alpha)$ cross section in the $1 / \mathrm{v}$ energy region can be determined from this measurement. The experiment will be done on a guide tube at the NIST reactor's Cold Neutron Research Facility which employs a liquid hydrogen moderator. A pyrolytic graphite monochromator with a beryllium filter is being designed for this work. The monochromator will have an energy uncertainty of $0.1 \%$ and an energy spread of $1 \%$. Backgrounds should be small since the guide tube allows the experiment to be done far from the reactor. A well characterized liquid sample is being prepared for this work.

[1] R.A. Schrack, O.D. Wasson, D.C. Larson, J.K. Dickens and J.H. Todd, Nuclear Science and Engineering 114, 352 (1993). 


\section{Oak Ridge National Laboratory}

Contact: M.S. Smith

Physics Division, Building 6010, MS-6354

Oak Ridge National Laboratory, P.O. Box 2008

Oak Ridge, Tennessee 37831-6354

The Nuclear Astrophysics Research Group at Oak Ridge National Laboratory carries out a program of Experimental Measurements, Theoretical Nuclear Astrophysics, and Nuclear Data Evaluation. The experimental work includes work at two facilities: the Holifield Radioactive Ion Beam Facility (HRIBF), and the Oak Ridge Electron Linear Accelerator (ORELA).

\section{Experimental Measurements at HRIBF}

\section{M.S. Smith (Oak Ridge National Laboratory)}

HRIBF is a new national user facility which - when operation begins in late 1996 - will provide beams of radioactive isotopes for research in nuclear astrophysics as well as nuclear structure and reaction physics. At HRIBF, we will make some of the first direct measurements of nuclear reactions on proton-rich radioactive isotopes that occur in stellar explosions such as novae, supernovae, and $\mathrm{X}$-ray bursts. Beams of ${ }^{17,18} \mathrm{~F}$ are currently under development for these astrophysics studies, and the measurements will be carried out at an experimental station built around the Daresbury Recoil Separator. More information on the experimental program can be found in ref. [1].

\section{Experimental Measurements at ORELA}

\section{P.E. Koehler and J.C. Blackmon (Oak Ridge National Laboratory)}

ORELA was transferred to the ORNL Physics Division in 1994 and is run approximately 4 8 weeks per year for nuclear astrophysics research. Capture and transmission cross sections are measured with neutrons from this pulsed white neutron source, which offers high neutron fluxes at the energies of interest to astrophysics ( $10 \mathrm{eV}$ to $2 \mathrm{MeV}$ ) as well as excellent neutron-energy resolution through long time-of-flight distances. These measurements are important for studies of heavy element nucleosynthesis through the $\mathrm{s}-\mathrm{r}-$, and $\mathrm{p}$-processes. Recently, s-process measurements have been made on ${ }^{13,136} \mathrm{Ba}(\mathrm{n}, \gamma)[2],{ }^{142,144} \mathrm{Nd}(\mathrm{n}, \gamma)$, and ${ }^{116,120} \mathrm{Sn}(\mathrm{n}, \gamma)$. A measurement of the ${ }^{7} \mathrm{Li}(\mathrm{n}, \gamma)$ reaction, important for the solar neutrino problem, has also recently been completed [3]. S-process measurements on Pt isotopes are planned for FY 1997.

[1] M.S. Smith, Nuclear Instruments and Methods B99 (1995) 349.

[2] P.E. Koehler et al., Physical Review C54 (1996) 1463.

[3] J.C. Blackmon et al., Physical Review C54 (1996) 383. 


\title{
Ohio University
}

\author{
Contact: S.M. Grimes and T.N. Massey \\ Department of Physics \\ Ohio University \\ Athens, Ohio 45701
}

\section{Neutron Production from Be+p and Be+d}

T.N. Massey, S.M. Grimes and T. Covell (Ohio University), B.J. Micklich, L. Sagalovsky and D.L. Smith (Argonne National Laboratory) and J. Yanch and W. Howard (Massachusetts Institute of Technology)

The production of neutrons from stopping targets of beryllium by both protons and deuterons is of interest for applied and medical physics. This work has been a collaboration with Argonne and MIT. To investigate the production of neutrons from a stopping beryllium target, we have made measurements with both NE213 and lithium glass detectors. The neutron production from proton bombardment of beryllium is being considered as a source reaction for the boron neutron therapy treatment of cancer. Thus, the low energy portion of the spectrum is extremely important.

We have completed measurements at incident energies of 2.0-5.0 MeV. Of special interest in our preliminary results is the relative importance of the low energy $(<1.0 \mathrm{MeV})$ neutrons produced from inelastic scattering to the first and second excited states of ${ }^{9} \mathrm{Be}$. We have completed precision measurements of the angular and energy dependence of neutrons from the ${ }^{9} \mathrm{Be}(\mathrm{d}, \mathrm{n})$ reaction at incident deuteron energies of 2.6, 3.0, 3.4, 3.8, 4.2, 4.6, 5.0, 5.4, 5.8, 6.2, 6.6 and $7.0 \mathrm{MeV}$ using NE213 detectors. We have reduced the statistical accuracy of the measurement to under $1 \%$ for measurements using NE213 detectors. A measurement of the low energy neutrons has been completed from 3.0 and $7.0 \mathrm{MeV}$ incident deuteron energy using a $\mathrm{Li}$ glass detector array.

\section{Study of the $A l(d, n)$ and $B(d, n)$ Reactions}

J.F. Guillemette, J.E. O'Donnell, F.B. Bateman, T.N. Massey and S.M. Grimes (Ohio University)

We have measured the spectral distribution of neutrons from the reaction ${ }^{27} \mathrm{Al}(\mathrm{d}, \mathrm{n})$ on a pure stopping aluminum target. At 7.44-MeV incident deuteron energy, measurements were made at 90 , 110 and 120 degrees using NE213 detectors. Further measurements were made at 120 degrees using $a^{235} U$ fission chamber provided by Argonne National Laboratory. The absolute neutron fluence was determined at each energy bin to better than $5 \%$. Additional experiments are planned to improve the absolute normalization of the spectra and improve the statistics for energies below $200 \mathrm{keV}$ and above $10 \mathrm{MeV}$. Measurement of the ${ }^{9} \mathrm{Be}(\mathrm{d}, \mathrm{n})$ spectral distribution is also planned to develop a secondary standard for energies below $0.5 \mathrm{MeV}$. As a practical application for this work, the $\mathrm{Al}(\mathrm{d}, \mathrm{n})$ reaction is being developed as a reference standard spectrum for detector efficiency calibrations. The spectrum at 120 degrees and 7.44-MeV incident energy was used to obtain the detector efficiency from 0.2 to $15.0 \mathrm{MeV}$ for the investigation of the $\mathrm{Be}(\mathrm{d}, \mathrm{n})$ spectrum mentioned above. 


\section{Studies of the Deuteron Optical Model}

T.N. Massey and S.M. Grimes (Ohio University)

An investigation into the deuteron optical model near the Coulomb barrier in ${ }^{56} \mathrm{Fe}$ and ${ }^{27} \mathrm{Al}$ is in progress. We have completed initial measurements of the neutron, proton, deuteron and alpha channels at energies from 2.5 to $7.0 \mathrm{MeV}$. This set of data includes all of the open channels available in the bottom part of this energy range. The result of these studies will help improve our knowledge of transmission coefficients near the Coulomb barrier for Hauser-Feshbach calculations.

\section{Shell-model Determination of Reaction-channel Widths}

\section{S.M. Grimes and T.N. Massey (Ohio University)}

We have developed a technique of calculation of the widths of various reaction channels using wave functions obtained from shell model diagonalization. These widths are then used to predict the cross section of reactions which cannot be directly measured. We have extensively studied the ${ }^{10} \mathrm{Be}$ and ${ }^{14} \mathrm{C}$ compound nuclei and are beginning studies of ${ }^{11} \mathrm{~B}$ and ${ }^{12} \mathrm{~B}$. These will be studied with $(p, n)$ and $(d, n)$ reactions on ${ }^{10} \mathrm{Be}$ target. 


\section{Pacific Northwest Laboratory}

Contact: P.L. Reeder.

MS P8-08

Pacific Northwest Laboratory

Richland, Washington 99352

Beta Decay Half-Lives and Delayed Particle Emission for Very Neutron-rich, Light-mass Nuclides

P.L. Reeder, Y. Kim, W.K. Hensley, H.S. Miley, R.A. Warner and Z.Y. Zhou (Pacific Northwest Laboratory) and D.J. Vieira, J.M. Wouters and H.L. Siefert (Los Alamos National Laboratory)

The results of an investigation described in some detail in the 1995 report have been presented at the International Conference on Exotic Nuclei and Atomic Masses, Arles, France [1].

[1] P.L. Reeder, Y. Kim, W.K. Hensley, H.S. Miley, R.A. Warner and Z.Y. Zhou, D.J. Vieira, J.M. Wouters and H.L. Siefert, Proceedings of the International Conference on Exotic Nuclei and Atomic Masses, Arles, France, 19-23 June, 1995, eds. M. de Saint Simon and O. Sorlin, Editions Frontieres, ISBN 2-86332-186-2. 


\title{
University of California-Davis
}

\author{
Contact: J.L. Romero \\ Physics Department \\ University of California-Davis \\ Davis, California 95616
}

\section{Hydrogen and Helium Inclusive Spectra Produced By Neutron-induced Reactions with Silicon at 50.0 and $32.2 \mathrm{MeV}$ \\ P.S. Rezentes, C.M. Castaneda, J.L. Romero, J.D. Drummond and T.A. Cahill (University of California-Davis) and Henry H.K. Tang (IBM East Fishkill Laboratory)}

Inclusive spectra of protons and Helium from neutron-induced reactions with ${ }^{28} \mathrm{Si}$ have been measured at several angles from $15 \mathrm{deg}$. to $90 \mathrm{deg}$. using a set of three $\mathrm{dE}-\mathrm{E}$ telescopes. The spectra were corrected for energy and particle loss that result as the charged particles escape the target. The double-differential cross sections are compared with pre-equilibrium predictions from the Cascade-Statistical model NUSPA of $\mathrm{H}$. Tang. With a light-mass target nucleus and relatively low-energy incident beams, this work presents a stringent test for the Cascade-Statistical model and results in moderate agreement with the data.

\section{Fragmentation of Silicon Induced by $80-\mathbf{M e V}$ Protons Using Reverse Kinematics}

J.L. Romero, F.P. Brady, D.A. Cebra, J. Chance, J. Kintner and J.H. Osborne (University of California-Davis), D.J. Morrissey, M. Fauerbach, R. Pfaff, C. Powell and B.M. Sherrill (Michigan State University) and Henry H.K. Tang (IBM East Fishkill Laboratory)

The objective of an experiment with a proton beam is to obtain isotopic double differential cross sections (in angle, energy, $Z$ and $A$ ) for the inclusive ${ }^{28} \mathrm{Si}(\mathrm{p}, \mathrm{F}) \mathrm{x}$ reaction initially at a proton energy of $80 \mathrm{MeV}$ and for about $F \geq 12$. Here $F$ is the mass number of the outgoing nucleus from the fragmentation of ${ }^{28} \mathrm{Si}$ and $\mathrm{x}$ stands for anything else. The energy spectra for the products $\mathrm{F}$ are needed over nearly the complete kinematic range at a number of angles. Alternatively, this can be accomplished by using reverse kinematics on a $\mathrm{CH}_{2}$ target (and on a $\mathrm{C}$ target for background). The main characteristics and advantages of the use of reverse kinematics are well known: the heavy fragments tend to have relatively low energies in the projectile frame. Thus, in the lab frame the fragments tend to lie in a forward cone. For example, the fragments with $11<\mathrm{F}<28$ lie mainly in a $7 \mathrm{deg}$. cone for the case of incident beam energy equal to $80 \mathrm{MeV}$ per nucleon. Lighter fragments of higher energy in the projectile frame tend to spread to larger angles and can be measured in nucleon-induced kinematic cases.

Differential cross sections of charged fragments near 0 degree were measured for the ${ }^{1} \mathrm{H}\left({ }^{28} \mathrm{Si}, \mathrm{F}\right) \times$ reaction at $80 \mathrm{MeV} /$ nucleon, using the $\mathrm{A} 1200$ zero-degree spectrometer at $\mathrm{NSCL}$. $\mathrm{CH}_{2}$ and $\mathrm{C}$ targets were used. The fragments detected ranged from $\mathrm{A}=5$ through $\mathrm{A}=28$. Results for selected fragments $\left({ }^{10} \mathrm{Ne},{ }^{24} \mathrm{Mg}\right.$, and $\left.{ }^{27} \mathrm{Al}\right)$ have been compared with an intranuclear cascade-statistical model developed by Henry Tang at I.B.M (code NUSPA). Good agreement in width and absolute 
cross section between theory and experiment is achieved without ad hoc adjustments. A full analysis of the experiment including all fragments (about 60 ) is in progress. The overall objective is to characterize the heavy recoils in proton-induced reactions and to complement previous studies of light ions from reactions like ${ }^{28} \mathrm{Si}(\mathrm{p}, \mathrm{x})$. Due to applications such as single event upsets in microelectronic systems and dosimetry problems in particle beam-based radiology, there are new demands for recoil data, especially in the energy regime around $100 \mathrm{MeV} /$ nucleon. This work demonstrates the feasibility of reverse kinematics as an accurate means to obtain recoil spectra. This is also the first experiment of a projected program involving similar measurements using $\mathrm{O}, \mathrm{N}$ and $\mathrm{C}$ beams. 


\section{University of Kentucky-Lexington}

Contact: M.T. McEllistrem

Department of Physics and Astronomy

University of Kentucky

Lexington, Kentucky 40506-0055

\section{Methods Developments in Nuclear Structure with Neutrons}

\section{Coincidence Methods in Gamma Rays from Neutron Scattering, and Lifetime Studies via DSAM}

C. McGrath, Minfang Yeh, P. Garrett and T. Belgya (Institute of Isotopes, Budapest, Hungary) and S.W. Yates (University of Kentucky)

A shielded three-detector array has been used for coincidence studies of gamma rays from neutron inelastic scattering. The problem with such an array lies in adequately collimating the neutrons to allow the detectors proximity to the sample being irradiated with minimal radiation dose to the detectors. A modified form of Spencer-design, forced reflection collimator was used. It provided a flux of neutrons with a $2 \mathrm{~cm}$ diameter at the collimator exit. Beyond the illuminated 2-cm space, the flux fell off by a factor of 10,000 within $1 \mathrm{~mm}$ of the edge of the collimator for $3-\mathrm{MeV}$ neutrons, and fell off to $1.5 \%$ of full illumination for $6 \mathrm{MeV}$ neutrons. The $50+\% \mathrm{Ge}$ detectors were placed within a few $\mathrm{cm}$ of the scattering sample, without subjecting the detectors to a high neutron flux.

A single BGO-shielded anti-compton spectrometer is used, also with a $50+\%$ Ge detector, to measure lifetimes via the DSAM method for collective excitations in heavy nuclei. Lifetimes in the range of $10 \mathrm{fs}$ to $1 \mathrm{ps}$ are routinely determined; these are quite appropriate for collective levels of heavy and mid-mass nuclei.

\section{Self-shielding Corrections for Neutron Total Cross Sections}

Zuying Zhou (Atomic Energy Institute of China, Beijing, China), M.T. McEllistrem and J.L. Weil (University of Kentucky) and R.R. Winters (Denison University)

Neutron total cross sections measured with thick absorbers and neutron energy spreads greater than the resonance widths must be corrected for resonance self-shielding effects to account properly for the energy-dependent. effective thicknesses of the absorbers, and thus extract accurate energy-averaged cross sections. The Monte-Carlo code SESH had been developed reliably for neutron energies in the $\mathrm{eV}$ and few-keV regions. But for even- $\mathrm{A}$ nuclei these corrections are important up to several hundreds of $\mathrm{keV}$, or even up to $0.5 \mathrm{MeV}$. The code is being revised so that it can be used correctly up to neutron energies of several $\mathrm{MeV}$ for nuclei in the tin region. $\mathrm{R}$-function methods are used to extract input resonance parameters from the scattering matrix elements of an optical potential which fits the total and elastic scattering cross sections. The code provides the needed corrections and, as a self-consistency check, the Monte-Carlo resonance parameters are also used to calculate a 'Monte-Carlo' scattering matrix. 


\section{Collective Levels in and near Rare Earths via $\left(n, n^{\prime} \gamma\right)$ Studies}

\section{Studies of Even-A Xe Isotopes}

C. McGrath, M. Yeh, M. Li, P. Garrett and S.W. Yates (University of Kentucky)

Studies of low-lying levels of several Xe isotopes were completed using $50 \mathrm{~g}$ of natural abundance xenon-diflouride. Coincidence studies were important to separate transitions for the different isotopes in this sample, with four isotopes of appreciable abundance. The first-excited $0+$ level of ${ }^{134} \mathrm{Xe}$ was identified. It and other levels show that ${ }^{134} \mathrm{Xe}$ resembles a spherical vibrator, whereas ${ }^{132} \mathrm{Xe}$ is more like a gamma-soft vibrator. Lifetimes were measured for several levels of ${ }^{132} \mathrm{Xe}$ and ${ }^{134} \mathrm{Xe}$. The three-detector coincidence system was essential not only to separate Xe isotopes, but also to avoid confusion with the abundant gamma rays from ${ }^{19} \mathrm{~F}$.

\section{Band Structures in ${ }^{166} \mathbf{E r}$}

P. Garrett, M. Yeh, Min Li, V. Sorokin, C. McGrath, M. Kadi and S.W. Yates (University of Kentucky) and H. Lehmann, J. Jolie, J. Kern, S. J. Mannanal and N. Warr (Institute of Physics, University of Fribourg, Switzerland)

Two-gamma-phonon states are expected to form bandheads of a $\mathrm{K}=4$ band throughout the rare earth region, or for a selected small set of nuclei, depending upon the model employed. Either approach predicts their existence in ${ }^{166} \mathrm{Er}$. Two experiments were undertaken to explore the possible two-gamma-phonon states in ${ }^{166} \mathrm{Er}$, and to obtain lifetimes for several levels in that nucleus. The $(\alpha, 2 \mathrm{n} \gamma)$ experiment on a ${ }^{164} \mathrm{Dy}$ target preferentially populates higher-spin states, up to $\mathrm{I}=16$. This experiment was executed at the Paul Scherrer Institute (PSI) in Switzerland. The (n,n' $\gamma)$ study populates lower-spin states, with $I<7$. It also provides lifetimes for states with mean lives less than $1 \mathrm{ps}$. A $98 \%$ isotopically-enriched sample was used for both experiments.

A filter was employed in looking for two-gamma-phonon states in coincidence data by seeking transitions in coincidence with the gamma bandhead and the $3+$ level decays. Through examinations of branching ratios and lifetimes for those levels decaying through either the $2+$ or $3+$ members of the gamma band, it is ascertained with high probability that the $2028-\mathrm{keV}$ level is the $\mathrm{K}=4$ bandhead.

\section{"Nearly" Complete Spectroscopy of ${ }^{112} \mathrm{Cd}$}

P.E. Garrett, H. Lehmann and J. Jolie (Fribourg University, Switzerland) and Min Li, C. McGrath, V. Sorokin, Minfang Yeh and S.W. Yates (University of Kentucky)

The ${ }^{112} \mathrm{Cd}$ nucleus has been the subject of intense investigation as it is one of the best examples of a U(5) symmetry subgroup, or spherical vibrator nucleus. However, it was not known how high in excitation energy this collective character survives, as level lifetimes had not been measured for states above $1.5 \mathrm{MeV}$ excitation energy. The initial aim of a series of $\left(n, n^{\prime} \gamma\right)$ measurements was then determination of lifetimes for proposed three-phonon states. Angular distributions at several incident neutron energies, excitation functions and gamma-gamma coincidences were all measured. 
Results of the measurements show that the collectivity remains intact for the spin 3 and 4 members of the quintet, but no $2+$ member survives. The experimental results are reasonably reproduced, including the fragmentation of the $2+$ state strength, by IBM-2 calculations.

Also observed are relatively large B(M1) strengths for two $2+$ levels near 2.2-MeV excitation energy which also have enhanced E2 decays to a low-lying 2+ intruder state. The levels with enhanced E2 decays are interpreted to be main fragments of the lowest 2+ mixed symmetry state, which appears to mix strongly with the second $2+$ state of the intruder configuration. This is the first firm evidence of mixed-symmetry $2+$ states in a good U(5) nucleus. Analysis of the data to date reveals many levels up to $4 \mathrm{MeV}$ excitation energy for which spins and lifetimes can be determined. A nearly complete level scheme for $\mathrm{I}<7$ up to about $3.5-\mathrm{MeV}$ excitation energy should be possible.

\section{Multi-phonon Excitations near ${ }^{208} \mathrm{~Pb}$}

\section{Levels and Transitions in ${ }^{208} \mathrm{~Pb}$}

Minfang Yeh, P. E. Garrett, M. Kadi, Gang Chen, Min Li, V. Sorokin, C. McGrath and S.W. Yates (University of Kentucky)

A $2626-\mathrm{keV}$ transition has been identified feeding the $2614.5-\mathrm{keV} \mathrm{J} \pi=3$ - first-excited level. Special care was taken with pulse shapes in amplifiers to be able to separate cleanly this incredibly weak transition just at the foot of the extraordinarily intense $2614.5-\mathrm{keV} 3-$ decay. The $2626-\mathrm{keV}$ transition has a threshold for excitation that clearly shows it is a decay to the first-excited $2614.5-\mathrm{keV}$ level. The isotropy of the angular distribution of this very weak line together with the small excitation cross section in neutron scattering are consistent only with a $0+$ assignment. It seems highly likely that the $2626-\mathrm{keV}$ transition depopulates the $0+$ state known primarily from internal conversion measurements.

An earlier report from another laboratory of a $2485-\mathrm{keV}$ transition, reputed to be the decay from a two-octupole phonon state in ${ }^{208} \mathrm{~Pb}$, is here shown not to belong to ${ }^{208} \mathrm{~Pb}$. The $2626-\mathrm{keV} 0+$ to 3- transition, when considered with the $2614.5-\mathrm{keV}$ de-excitation of the 3- first-excited level, forms a cascade of two E3 transitions which is the characteristic signature of a two-octupole phonon state. Thus, this is the first clear identification of a multi-phonon E3 excitation in a non-deformed nucleus.

Ten new levels have been discovered in ${ }^{208} \mathrm{~Pb}$, and many lifetimes have been measured. Coincidence work with the three-detector coincidence array was very helpful in fixing the decay schemes of the newly-discovered levels.

\section{Levels and Decay Schemes in ${ }^{206} \mathrm{~Pb}$}

Min Li, Gang Chen, P.E. Garrett, D. Wang, J.L. Weil and M.T. McEllistrem (University of Kentucky)

Four new levels have been discovered in ${ }^{206} \mathrm{~Pb}$ via the (n,n' $\gamma$ ) reactions on an $88 \%$ isotopicallyenriched sample. The levels were discovered in the excitation-energy region between $2.9 \mathrm{MeV}$ and 4.5 MeV. Angular distribution measurements allow spin assignments to be fixed for several levels, and spin-limitations for several others. Many lifetimes have been determined for excited levels of this 
nucleus. Part of the role of these gamma-ray detection measurements is to supplement neutrondetection measurements of scattering to excited levels between 3- and 5-MeV excitation energy. The energy resolution of the TOF neutron spectra is much less than necessary to separate individual levels. The $2-\mathrm{keV}$ resolution of the gamma-ray detection data enables the separation not achievable in neutron detection. Many level-lifetimes have also been measured in this nucleus using Doppler Shift attenuation methods.

\section{Levels and Transition Rates in ${ }^{207} \mathbf{P b}$}

M. Kadi, P.E. Garrett, Minfang Yeh, Min Li, V. Sorokin and S.W. Yates (University of Kentucky)

Fast E1 transitions from multi-phonon excitations in even-A nuclei can signal the presence of strong collectivity, and help particularly to identify multi-phonon excitations, particularly those of odd-parity. But what is meant by 'fast' E1 transitions must be identified in each mass region. The transitions amongst low-lying levels of ${ }^{207} \mathrm{~Pb}$ are dominantly single particle, and thus E1 transitions from them serve to calibrate rates in the $\mathrm{Pb}$ region. Early measurements of transitions in ${ }^{207} \mathrm{~Pb}$ indicate that there are at least several lifetimes which fall within the range between $10 \mathrm{fs}$ and $1 \mathrm{ps}$, the range susceptible to our DSAM measurements.

\section{Other Gamma-ray Transition Experiments}

Levels and Transition Rates in. ${ }^{116} \mathrm{Sn}$ and ${ }^{120} \mathrm{Sn}$

V. Sorokin and Zoltan Gacsi (Institute of Nuclear Studies, Debrecen, Hungary) and J.L. Weil (University of Kentucky)

A rather complete level scheme and decay scheme have been published from our laboratory for

${ }^{116} \mathrm{Sn}$; but lifetimes were not determined at that time. Now many level-lifetimes are being measured in this nucleus, as well as in ${ }^{120} \mathrm{Sn}$. Suggestions that sets of levels of these nuclei can be associated with collective excitations can be reinforced or rejected based on lifetimes for electromagnetic decay of the levels. The level and decay schemes of ${ }^{120} \mathrm{Sn}$ are now also being determined.

\section{Transition Rates in ${ }^{124} \mathrm{Sn}$}

V. Sorokin and Zoltan Gacsi (Institute of Nuclear Studies, Debrecen, Hungary) and J.L. Weil (University of Kentucky)

Several promising candidates for a three-quadrupole-phonon quintet were identified in early work on level and decay schemes found through $\left(n, n^{\prime} \gamma\right)$ work. Attempts will be made to determine decay transition rates to confirm or reject these tentative identifications. Transition rates will be measured with DSAM techniques. 


\section{Levels and Transition Rates in ${ }^{142} \mathrm{Ce}$ and in ${ }^{142} \mathrm{Te}$}

J.R. Vanhoy, J.M. Anthony, B.M. Haas, B.H. Benedict and B.T. Meehan (U.S. Naval Academy) and Sally F. Hicks, C.M. Davoren and C.L. Lundstedt (University of Dallas)

The excited levels of ${ }^{142} \mathrm{Ce}$ and the transitions between these levels have been studied using the $\left(n, n^{\prime} \gamma\right)$ reaction. Gamma-ray yields vs. incident neutron energy (excitation functions), angular distributions, and Doppler shifts were measured for gamma rays from levels up to 3.3-MeV excitation energy. Substantial fragmentation of fixed symmetry strength was discovered and quantified for $2+$ states, and successfully reproduced in a couple of collective excitation models. Candidate levels for the two-quadrupole-phonon triplet, the three-quadrupole-phonon quintet, and the quadrupole-octupole coupled-phonon quintet have all been identified.

Studies of mixed-symmetry fragmentation and multi-phonon excitations in ${ }^{124} \mathrm{Te}$ are in progress. Angular distributions and some excitation functions have been measured to date.

Neutron Inelastic Scattering Differential Cross Sections and Separating Neutron and Proton Transition Matrix Elements

\section{Neutron Scattering in ${ }^{140} \mathrm{Ce}$ and ${ }^{142} \mathrm{Ce}$}

Gang Chen, Min Li, J.L. Weil and M.T. McEllistrem (University of Kentucky)

Elastic and inelastic scattering cross sections have been measured for the two Ce isotopes using separated-isotope samples at an incident energy of $7.5 \mathrm{MeV}$. Evaluation of the cross sections and comparison with the electromagnetic transition rates enables determination of the ratio of transition matrix elements separately for neutrons and protons for the first excited level in ${ }^{140} \mathrm{Ce}$. The excitations show neutron dominance for both the $2+$ and 3- excited levels of ${ }^{140} \mathrm{Ce}$, and also for the $2+$ level of ${ }^{142} \mathrm{Ce}$. But the 3- excitation is dominated by neutrons in ${ }^{142} \mathrm{Ce}$.

Separate Neutron and Proton Transition Matrix Elements in Scattering from ${ }^{206} \mathbf{P b}$ and ${ }^{208} \mathbf{P b}$

Min Li, Gang Chen, P.E. Garrett, Minfang Yeh, J.L. Weil and M.T. McEllistrem (University of Kentucky)

The excitation strengths for the first 3- level of both nuclei and the first $2+$ of ${ }^{206} \mathrm{~Pb}$ have been well determined in previous neutron-scattering experiments. The mean field characterizing scattering is also well fixed. But inelastic scattering for higher collective excitations, like the first $2+$ and 5 - of ${ }^{208} \mathrm{~Pb}$ and the second $2+$ of ${ }^{206} \mathrm{~Pb}$ has not been measured. In addition, there are suggestions that collective excitations of unknown character exist for levels between 4 and $5 \mathrm{MeV}$ excitation energy in both nuclei. The present scattering study is directed to resolving these issues. Elastic- and inelasticscattering cross sections have been measured for both nuclei, and are being analyzed for characterization of mean fields and collective strengths to these higher excited levels. These neutrondetection experiments are substantially aided by the availability of high-resolution gamma-ray detection data from the associated $\left(n, n^{\prime} \gamma\right)$ studies. 


\section{Applied Physics Projects}

\section{Improved Accuracy for Fe(n,n' $\gamma)$ Cross Sections}

J.K. Dickens (Oak Ridge National Laboratory) and Min Li, J. Kuhr, J.D. Robertson and M.T. McEllistrem (University of Kentucky)

Gamma-ray production cross sections for inelastic scattering to the first-excited level of ${ }^{56} \mathrm{Fe}$ are important for understanding the transmission of neutron flux through thick reactor pressure vessels. For this reason, improved accuracy of these cross sections over the neutron-energy interval from about $1 \mathrm{MeV}$ to about $4 \mathrm{MeV}$ have been declared a priority by an IAEA working group. These gamma-ray production cross sections were measured at the University of Kentucky fifteen years ago, but with uncertainties of about $8 \%$, and only over the range from $2.5 \mathrm{MeV}$ to about $4 \mathrm{MeV}$. A new project has been started to measure these cross sections to an accuracy of about $3 \%$ by comparing them to the rather well known ${ }^{10} \mathrm{~B}(n, \alpha)$ cross sections. For this purpose special samples have been prepared at $\mathrm{ORNL}$ with mixed $\mathrm{Fe}$ and $\mathrm{B}$ components. These samples seem to be $\mathrm{Fe}_{3} \mathrm{~B}$, but their actual $\mathrm{B}$ to $\mathrm{Fe}$ atom-ratios are now being determined by neutron inelastic scattering in pure $\mathrm{Fe}$ and pure $\mathrm{B}$ samples, as well as that in the mixed samples. The ratio is also being determined by inductivelycoupled plasma atomic emission spectrometry (ICPAES).

Gamma-ray production yields have been measured for both the (n,n'y) reactions in $\mathrm{Fe}$ and for the ${ }^{10} \mathrm{~B}(\mathrm{n}, \alpha \gamma)$ reaction, simultaneously, as an early phase of the project. Measurements extend from $1.24 \mathrm{MeV}$ to $2.6 \mathrm{MeV}$ at present: Measurements and checks for uncertainties are continuing.

\section{Test of Corrosion through Neutron Scattering}

George Charatis (Penetron Corp., Ann Arbor, MI), M.T. McEllistrem (University of Kentucky),

A.B. Flowers (Gas Research Institute, Chicago, IL) and Ron Dreftz (Illinois Institute of Technology Research Corp., IL)

A special project to explore our ability to analyze subsurface materials through measuring neutron elastic back scattering has been launched. Using neutrons of energy near $3 \mathrm{MeV}$ we have shown that the carbon content of carbon-iron pipe can be fixed at the 3-4\% level with an uncertainty of less than or equal to $5 \%$ of the ratio through such scattering methods.

\section{Luggage and Cargo Inspection for Airports through Neutron}

Transmission Measurements

Peter Van Staagen, Cameron Gibson and T. Gill Miller (Tensor Technology Corp., Madisonville, $A L$ ) and M.T. McEllistrem (University of Kentucky)

A multi-detector array for measurement of neutron absorption in luggage and cargo has been developed by the Tensor Technology Corp. and is being enlarged and further developed and tested at the University of Kentucky accelerator laboratory. 'White Source' neutron methods are used with neutrons from the $B e(d, n)$ reaction on a thick $B e$ target. Neutrons from about 0.7 to about $4.0 \mathrm{MeV}$ are present in sufficient intensity to be used for transmission measurements and analyses. The transmission measurements are analyzed with neural net computational methods to ascertain the 
element composition of objects through which the neutrons have passed. To date single detector tests have been done, as well as tests with a 24 detector array.

Multi-detector arrays complicate the detection problem because of the possibility of interferences between detectors. The resultant problems are being addressed. The purpose of this project, of course, is strengthened airport security for intervention against explosives and drugs.

\section{Monte Carlo Tests of Absorbed Dose from Electron Irradiations}

J.O. Deasy, H.C. Park and Peter Almond (Brown Cancer Center, University of Louisville, KY) and M.T. McEllistrem (University of Kentucky)

Electron depth-dose curves, the measure of the depth of penetration and localization of dose in the body from electron therapy, are normally determined from direct measurement of ionization in water and tissue-equivalent phantoms with small ion chambers; in other words, from a rather direct measurement of absorbed dose. Earlier studies by some of the above authors have focussed on measurements of the properties of electron beams as they emerge from electron accelerators, with nominal energies from 6 to $20 \mathrm{MeV}$. The question now being explored is whether accurate knowledge of electron energies, and the distribution of electron energies entering a phantom, would permit prediction of the absorbed dose with an accuracy sufficient for treatment planning purposes. Predictions are attempted with Monte Carlo methods. The answer is in the affirmative, provided the accelerator has beam-energy defining slits at the image of its analysis magnet, so that the mean energy is precisely and stably controlled. 


\title{
University of Massachusetts-Lowell
}

\author{
Contact: J.J. Egan \\ Department of Physics and Applied Physics \\ University of Massachusetts-Lowell \\ Lowell, Massachusetts 01854
}

\section{Neutron Scattering Data and Fission Spectrum Measurements}

G.H.R. Kegel, J.J. Egan, A. Mittler, D.J. DeSimone, C. Narayan, M. O'Connor, J. Chen, M.L. Woodring, Y.J. Ko, D.J. Souza, R.D. D'Alarcao and J.R. Tedesco (University of Massachusetts-Lowell) and P. Staples (Los Alamos National Laboratory)

\section{Neutron Scattering Cross Sections for Low Lying States In ${ }^{235} U$}

Differential elastic and inelastic cross sections have been measured for two-level groups in ${ }^{235} \mathrm{U}$, the ground state $+77-\mathrm{eV}+13-\mathrm{keV}$ states, and the $46.2-+51.7-\mathrm{keV}$ states, at incident neutron energies of 570 and $700 \mathrm{keV}$, covering an angular range from 35 to 135 degrees in 10-degree steps. The $700-\mathrm{keV}$ data were taken to enable comparison with the earlier measurements of Haouat $e t$ al. [1]. Data at both energies compare favorably with ENDF/B-VI.

\section{The ${ }^{14} N$ Inelastic Cross Section for the 2.313-MeV First-excited State}

The neutron induced gamma-ray production cross section for the first-excited state of ${ }^{14} \mathrm{~N}$ has been measured for neutron energies from 2.65 to $3.55 \mathrm{MeV}$ at $100-\mathrm{keV}$ intervals. An angular distribution of the gamma rays was measured at an incident neutron energy of $3.45 \mathrm{MeV}$. Prior measurements $[2,3,4]$ of the cross section in this energy region were sparse and had large uncertainties. The data of Bostrom et al. [2] taken in 1959 span the region from $3.4 \mathrm{MeV}$ upward in roughly 200-keV steps, while the measurements of Rogers et al. [3] and Beyster et al. [4] were made in coarse increments of approximately $1 \mathrm{MeV}$. A comparison with the ENDF/B-VI evaluation shows the Lowell data to be about 10 percent higher than ENDF up to the region around $3.5 \mathrm{MeV}$ where the data are a factor of 2 higher than ENDF. The data of Bostrom et al. [2] and Beyster et al. [4] also show this deviation from ENDF at this energy. The datum of Rogers et al. [3] at $3.5 \mathrm{MeV}$ measured with $0.5-\mathrm{MeV}$ energy resolution does not exhibit this deviation. The likely explanation for this behavior is the presence of a resonance in the cross section near $3.5 \mathrm{MeV}$ which is not accounted for in the evaluation and not observed with the coarse energy resolution of Rogers et al. [3]. This work has been submitted for publication.

Measurements of the Neutron-induced Fission Spectra of ${ }^{235} U$ and ${ }^{239} P u$ for Energies Less Than the Incident Energy

Our earlier work [5] on fission spectra for these isotopes reported measurements for energies greater than the incident energy in order to check the predictions of the Los Alamos model of Madland and Nix [6]. Measurements of neutron-induced fission spectra at energies below the incident 
energy have never been achieved due to the background caused by elastically and inelastically scattered neutrons.

We have now made measurements of the portion of the spectrum below the incident energy by employing three fast barium fluoride scintillation detectors in a coincidence arrangement to tag an event as a fission event. The barium fluoride gamma-ray detectors are deployed close to the fission sample and have sufficient resolution to separate, in a time-of-flight spectrum, gamma rays emanating from the neutron-producing lithium target, fission gamma rays from the sample located about $8 \mathrm{~cm}$ from the target, and neutrons from the target or from the sample. By setting a window on the fission gamma rays in this two-fold coincidence, barium fluoride time-of flight spectrum to signal the occurrence of a fission event, we are able to substantially reduce the background peaks due to elastic and inelastic neutron scattering in the neutron time-flight-spectrum obtained with a liquid scintillator. The spectra are further enhanced by making use of the pulse-shape discrimination capabilities of the scintillator.

Data are acquired in event mode using a Canberra 8223 analog multiplexer and Canberra 8713 ADC controlled by a specially developed circuit and interfaced to a PC. The data acquisition computer environment was written using MS Visual BASIC V1.0 with I/O routines in MS C V6.0. Fission spectra have been obtained down to $500 \mathrm{keV}$ for incident neutron energies of 1.5 and 2.5 $\mathrm{MeV}$. Further measurements at higher energies are planned.

\section{Interband Transitions Probabilities and Cross Sections for ${ }^{169} \mathrm{Tm}$ from $\left(n, n^{\prime}\right)$ and $\left(n, n^{\prime} \gamma\right)$ Reactions}

We are initiating a study of neutron scattering cross sections for ${ }^{169} \mathrm{Tm}$. Studies of nuclides such as ${ }^{169} \mathrm{Tm}$ will help to elucidate the effects of interband transitions and the extent of direct interaction contributions to the scattering mechanism in odd-A deformed nuclei. We have previously studied the odd-A actinides ${ }^{235} \mathrm{U}$ and ${ }^{239} \mathrm{Pu}$ which have a much more complicated band structure than neighboring even-A nuclides making experimental measurements and theoretical calculations of the cross sections much more difficult. The difficulty of measurements for ${ }^{235} \mathrm{U}$ and ${ }^{239} \mathrm{Pu}$ is exacerbated by the small mass of the scatterers available to us. Consequently we are looking into nuclei like ${ }^{169} \mathrm{Tm}$ which has a more tractable level scheme, is monoisotopic, and readily available to us in substantially larger quantities than ${ }^{235} \mathrm{U}$ of ${ }^{239} \mathrm{Pu}$, thus facilitating neutron scattering measurements. The simpler level scheme should also alleviate some of the problems encountered in theoretical calculations of the cross sections.

[1] G. Haouat et al., Nuclear Science and Engineering 81, 491 (1982).

[2] N.A. Bostrom et al., Neutron Cross Sections and Technology: Proc. of a Conference (1959), 31. Published by the National Bureau of Standards, p. 71 (1959).

[3] V.C. Rogers et al., Nuclear Science and Engineering 58, 298 (1975).

[4] J.R. Beyster et al., Neutron Cross Section Data for Radiation Transport Calculations, Gulf General Atomic Report GA-80006 (1969).

[5] P. Staples, J.J. Egan, G. H. R. Kegel, A. Mittle and M. L. Woodring, Nuclear Physics A591, 41 (1995).

[6] D.G. Madland and J.R. Nix, Nuclear Science and Engineering 62, 213 (1982). 


\title{
University of Wisconsin-Madison
}

\author{
Contact: H.H. Barschall \\ Department of Physics \\ The University of Wisconsin \\ Madison, Wisconsin 53706

\section{Nuclear Data for Radiotherapy} \\ H.H. Barschall (University of Wisconsin-Madison) and M.B. Chadwick (Los Alamos National \\ Laboratory)
}

There is strong evidence that radiation treatment with neutrons is the treatment of choice for certain types of cancer. For the neutrons to get to the treatment volume without too much attenuation, they must have high energies. For radiation treatment to be effective the radiation dose delivered to the treatment volume must have an accuracy of $5 \%$. The problem is that few neutron cross sections have been measured above $15 \mathrm{MeV}$ neutron energy so that calculations of the expected dose to the treatment volume have great uncertainty. For better treatment planning, both for calculations of neutron transport and for calculations of absorbed dose, one needs better information about the neutron cross sections of the components of tissue and of collimation and shielding materials.

Recently the International Commission on Radiation Units and Measurements (ICRU) has established a report committee on "Nuclear Data for Radiotherapy". This committee is charged with tabulating neutron cross sections of relevant elements up to neutron energies of $100 \mathrm{MeV}$, and nuclear cross sections of protons up to $250 \mathrm{MeV}$.

Since there are very few measurements above $15 \mathrm{MeV}$ neutron energy, model calculations will be used to interpolate and extrapolate from available measurements. Much of the work will be carried out by one of the authors (MC). He would appreciate receiving any new information about measurements of neutron cross sections above $15 \mathrm{MeV}$ and of nuclear cross sections of high-energy protons. 


\section{CSEWG Measurement and Basic Science COMMITTEE MEMBERSHIP}

Dr. H.H. Barschall

Department of Physics

The University of Wisconsin

Madison, Wisconsin 53706

Tel: (608)262-9569

Fax: (608)262-3598

EM: barschall@uwnuc0.physics.wisc.edu

Dr. Charles D. Bowman

H803

Los Alamos National Laboratory

Los Alamos, New Mexico 87545

Tel: (505)667-3600

Fax:: (505)665-4121

EM: cbowman@lampf.lanl.gov

Dr. Paul Brady

Physics Department

University of California - Davis

Davis, California 95616

Tel: (916)752-1793

Fax: (916)752-4717

EM: brady@ucdphy.ucdavis.edu

Dr. Allan D. Carlson

RADP-C311

NIST

Gaithersburg, Maryland 20899

Tel: (301)975-5570

Fax: (301)869-7682

EM: carlson@enh.nist.gov

Dr. Ed Cecil

Colorado School of Mines

Golden, Colorado 80401

Tel: (303)273-3736

Fax: (303)273-3919

EM: fcecil@mines.colorado.edu
Dr. James J. Egan

Department of Physics and Applied Physics

University of Massachusetts-Lowell

Lowell, Massachusetts 01854

Tel: (508)934-3780

Fax: (508)459-6561

EM: eganj@woods.ulowell.edu

Dr. Steven M. Grimes

T.N. Massey

Department of Physics

Ohio University

Athens, Ohio 45701

Tel: (614)593-1979

Fax: (614)593-1436

EM: grimes@oual4.phy.ohiou.edu

Dr. Robert C. Haight

Group P-15

MS-D406

Los Alamos National Laboratory

Los Alamos, New Mexico 87545

Tel: (505)667-2829

Fax: (505)667-0401

EM: haight@lampf.lanl.gov

Dr. Gunter H.R. Kegel

Radiation Laboratory

1 University Avenue

University of Massachusetts-Lowell

Lowell, Massachusetts 01854

Tel: (508)934-3280

Fax: (508)459-6561

EM: kegelg@aspen.uml.edu 
Dr. M. Aslam Lone

AECL-Research

Station 27, Physics Division

Nuclear Data and Models

Chalk River Laboratories

Chalk River, Ontario

Canada KOJ $1 \mathrm{JO}$

Tel: (613)584-3311 (x4007)

Fax: (613)584-1849

EM: lonea@crl.aecl.ca

Dr. Marcus T. McEllistrem

Physics and Astronomy

University of Kentucky

Lexington, Kentucky 40506-0055

Tel: (606)257-3403

Fax: (606)323-2846 .

EM: phy160@ukcc.uky.edu

Dr. Arthur Mittler

Department of Physics and Applied Physics

University of Massachusetts-Lowell

Lowell, Massachusetts 01854

Tel: (508)934-3775

Fax: (508)459-6561

EM: mittlera@woods.ulowell.edu

Dr. Paul L. Reeder

MS P8-08

Pacific Northwest Laboratory

Richland, Washington 99352

Tel: (509)376-0948

Fax: (509)372-0672

EM: pl-reeder@pnl.gov

Dr. Juan L. Romero

Physics Department

University of California - Davis

Davis, California 95616

E-M: romero@ucdphy.ucdavis.edu
Dr. Walter A. Schier

Department of Physics

University of Massachusetts-Lowell

Lowell, Massachusetts 01854

Tel: (508)934-3770

Fax: (508)459-6561

EM: Not Available

Dr. Donald L. Smith

TD-207-DB116

Argonne National Laboratory

Argonne, Illinois 60439

Tel: (630)252-6021

Fax: (630)252-1774

EM: donald.l.smith@anl.gov

Dr. Michael Smith

Physics Division

Building 6010, MS-6354

Oak Ridge National Laboratory

Oak Ridge, TN 37831-6354

Tel: (423)576-5037

Fax: (423)576-8746

EM: msmith@orph01.phy.ornl.gov

Dr. Ron Winters

Department of Physics

Denison University

Granville, Ohio 43023

Tel: (614)587-6227

Fax: (614)587-6417

EM: winters@max.cc.denison.edu 